\title{
PRODUÇÃO INTEGRADA DE ANONÁCEAS NO BRASIL ${ }^{1}$
}

\author{
RAIMUNDO BRAGA SOBRINHO 2
}

RESUMO - Os conceitos técnicos e operacionais contidos na Produção Integrada (PI) vêm atender de forma direta às exigências dos órgãos nacionais e internacionais que fiscalizam o comércio de "commodities", dando ênfase à segurança e a qualidade dos alimentos produzidos e consumidos pela população. A garantia da produção de um alimento seguro e rastreável é alcançada mediante o esforço harmônico de todos os integrantes da cadeia produtiva. Esse sistema pressupõe o cumprimento das Normas Técnicas Específicas (NTE) para cada produto, permitindo o controle efetivo do sistema produtivo agropecuário por meio do monitoramento de todas as etapas na cadeia produtiva. Esse conceito teve início com o Manejo Integrado de Pragas (MIP) e, posteriormente, expandiu-se para uma visão holística, estruturada em quatro pilares de sustentação: organização da base produtiva; sustentabilidade do sistema; monitoramento dos processos; e formação de um banco de dados. Dentro desta visão, insere-se a Produção Integrada de Anonáceas, projeto iniciado em 2010, com apoio do CNPq/MAPA/EMBRAPA e instituições parceiras. As anonáceas representam um nome genérico para designar as plantas da família Annonaceae constituída por cerca de 120 gêneros e em torno de 2.300 espécies. No Brasil, estão registrados 29 gêneros, dentro dos quais cerca de 260 espécies. Entre as espécies de maior importância comercial, destacam-se a graviola (Annona muricata L.), pinha (Annona squamosa L., cherimólia (Annona cherimólia, Mill.) e a atemoia, hibrido de A. cherimólia e $A$. squamosa. Essas frutas têm alta aceitação pelo seu sabor e possibilidade de uso para consumo in natura, sucos e geleias. As áreas comercialmente cultivadas são concentradas nos Estados do Nordeste do Brasil. Os Estados de maior concentração: Bahia para graviola e pinha, Alagoas para pinha e São Paulo para atemoia. Os resultados de pesquisa envolvendo toda a cadeia produtiva dessas culturas são ainda muito preliminares, necessitando, portanto, de maior concentração nas áreas de melhoramento, controle de pragas e doenças, fisiologia da produção e pós-colheita.

Termos para indexação: pinha, graviola, cherimólia, atemoia, rastreabilidade, pós-colheita.

\section{INTEGRATED PRODUCTION OF ANNONACEAE IN BRASIL}

\begin{abstract}
Technical and operational concepts within Integrated Production (IP) come to directly attend the requirements of national and international agencies which are in charge of inspection of commodities with focus on safety and quality of foods bought by consumers. The guarantee of producing a safe and traceable food is reached by harmonic effort of productive chain components. This must include following the Specific Technical Rules (STR) for each product allowing an effective control of the production systems by monitoring every phase of this productive chain. This concept begun with Integrated Pest Management (IPM) and, afterward expanded to a holistic vision based on four pillars: organization of the productive business; sustainable system; monitoring of the whole process; and formation of a data set. This vision includes the Integrated Production of Annonaceae, project that begun in 2010 supported by CNPq/MAPA/EMBRAPA and affiliated institutions. Annonaceae represents generic name to designate plants of Annonaceae family which has about 120 genus and about 2,300 species. In Brazil there is a register of 29 genus with 260 species. Among species of great commercial importance there are sour soup (Annona muricata L.), sweet apple (Annona squamosa L.), cherimoya (Annona cherimola Mill) and the atemoia, hybrid of $A$. cherimola and $A$. squamosa. These fruits area highly accepted due to their excellent taste and possible use as pulp for juices and others uses. Commercial areas are concentrated in the Northeast of Brazil. The largest plantations of sour soup and sweet apple are located in the state of Bahia, for sweet apple the state of Alagoas, and for atemoia the state of São Paulo. Research results for these four fruits are still very poor. Improvement has to be done on genetic, pest control, disease control, physiology of production and post harvesting.
\end{abstract}

Index terms: sweet apple, sour soup, cherimoya, atemoia, traceability, post harvesting.

\footnotetext{
${ }^{1}$ Palestra Anonáceas - V Congresso Internacional \& Encontro Brasileiro sobre Annonaceae: do gene à exportação (19 a 23 de Agosto de 2013). Botucatu-SP.

${ }^{2}$ Embrapa Agroindústria Tropical. Rua Dra. Sara Mesquita, 2270- CEP 60.511-110 Fortaleza - Ceará. E-mail: raimundo.braga@embrapa.br
} 


\section{INTRODUÇÃO}

A produção Integrada (PI) foi inicialmente abordada na década de setenta pela Organização Internacional para o Controle Biológico e Integrado contra os Animais e Plantas Nocivas (OILB). Discutiam-se naquele período as relações entre manejo das fruteiras e a proteção integrada dessas culturas, ficando evidenciada a necessidade de adoção de novos paradigmas que atendessem às exigências do agroecossistema de forma a utilizar associações harmônicas e inter-relacionadas com os sistemas de produção. Entretanto, somente a partir de 1993, a OILB publicou os princípios e as normas técnicas sobre esse tema que ainda hoje são usados como diretrizes gerais dos documentos pertinentes a esse assunto. Tendo por base essas premissas, países como a Alemanha, Suíça e Espanha foram pioneiros na adoção dos preceitos da PI na União Europeia. Isso surgiu da necessidade de substituir as práticas convencionais onerosas e obsoletas por um sistema com o foco em PI, com redução dos custos de produção, melhor qualidade dos alimentos produzidos e menor impacto ambiental (MAPA, 2008).

A partir de 1999, com a adequação das cadeias produtivas aos princípios de sustentabilidade, rastreabilidade e alimento seguro com foco na produção de frutas de alta qualidade, utilizando tecnologias e monitoramento para a racionalização no uso de insumos agrícolas, foi possível obter resultados satisfatórios na balança comercial brasileira de frutas. Com esse salto qualitativo, associado à abertura de novos mercados para as frutas brasileiras, o Brasil passou de importador para exportador de frutas. Nesse cenário, a Produção Integrada de Frutas (PIF) teve papel preponderante como agente dessa transformação. Os conceitos da PIF vieram de encontro aos preceitos básicos da Revolução Verde que tinha como premissa básica o uso intensivo de mecanização agrícola, fertilizantes químicos, agrotóxicos e manipulação genética. Já bem conhecido que tais sistemas de produção causaram intensa degradação ambiental, produção de alimentos com resíduos de agrotóxicos e redução na qualidade dos alimentos produzidos no campo (MAPA, 2008).

$\mathrm{Na}$ década de 70, iniciaram-se, na Europa, os primeiros trabalhos voltados para o Sistema de Produção Integrada de Frutas em resposta à necessidade de reduzir o uso de agrotóxico, priorizando a redução dos efeitos deletérios ao meio ambiente e ao homem. Nesse contexto, a OILB define a Produção Integrada como "o sistema de produção que gera alimentos e demais produtos de alta qualidade, mediante o uso dos recursos naturais e regulação de mecanismos para substituição de insumos poluentes e a garantia da sustentabilidade de produção agrícola; enfatiza o enfoque do sistema holístico, envolvendo a totalidade ambiental como unidade básica; o papel central do agroecossistema; o equilíbrio do ciclo de nutrientes; a preservação e o desenvolvimento da fertilidade do solo, e a diversidade ambiental como componentes essenciais.

O processo de globalização dos mercados evoluiu com as exigências da comercialização de produtos agropecuários produzidos sob a tutela de um protocolo de produção. Isso foi consequência do aperfeiçoamento dos mercados consumidores, mudança de hábitos alimentares e a procura por alimentos seguros. Para atender a essas demandas, protocolos do setor varejista foram implementados na Europa. Entre os mais conhecidos aparece o EUREPGAP, hoje expandido para GLOBALGAP (Good Agricultural Practices-GAP), que tem pressionado produtores e exportadores de frutas para seguirem as normas de produção com foco na redução do uso de insumos agrícolas, preservação do meio ambiente, rastreabilidade, resíduos de agrotóxico, condições de trabalho e higiene.

A adoção do sistema de Produção Integrada de Frutas teve uma aceitação e um avanço extraordinários, englobando vários sistemas produtivos em diversos países produtores de frutas. Na América do Sul, a Argentina foi o primeiro país a implantar o sistema PIF em 1997, seguido no mesmo ano pelo Uruguai e Chile. No Brasil, a implantação deu-se em 1998. Especificamente, no caso da PI Anonáceas (pinha, graviola e atemóia), o projeto foi iniciado em 2010, abrangendo os Estados de São Paulo, Bahia, Alagoas e Ceará. Este trabalho objetiva descrever os avanços obtidos com a implantação do projeto de Produção Integrada de Anonáceas no Brasil.

\section{AS ANONÁCEAS NO BRASIL}

As anonáceas representam um nome genérico para designar as plantas da família Annonaceae, constituída por cerca de 120 gêneros e em torno de 2.300 espécies. No Brasil, estão registrados 29 gêneros, dentro dos quais cerca de 260 espécies, sendo algumas de importância econômica. Entre as espécies de maior importância comercial, destacamse a graviola (Annona muricata L.), pinha, ata ou fruta-do-conde (Annona squamosa L.), cherimólia (Annona cherimólia Mill.) e a atemoia, híbrido de A. cherimoia e $A$. squamosa.

As anonáceas englobam um grupo de 
frutíferas de importância econômica em diversos países, como Chile, México, Venezuela, Austrália e Brasil. No Brasil, estas plantas são encontradas desde o Norte do país até o Estado de São Paulo. Foi na região semiárida do Nordeste do Brasil que o cultivo dessas fruteiras teve o maior avanço de área. Atualmente, os Estados da Bahia e Pernambuco apresentam plantios irrigados com boas produtividades. A Bahia é o principal produtor, seguido pelos Estados de Alagoas e São Paulo. O grande interesse pelo cultivo das anonáceas deve-se aos altos preços obtidos tanto da polpa como da fruta, com grande possibilidade de exportação.

A gravioleira é uma planta originária da América Central e ao norte da América do Sul. Pode ser encontrada disseminada em toda a faixa equatorial do planeta. É conhecida como "soursop" na língua inglesa, "guanabano" no idioma espanhol e "coros sol" em francês. No Brasil, foi introduzida pelos portugueses no século XVI. O Estado da Bahia é o maior produtor nacional. Os frutos chegam a pesar mais de oito quilogramas. A polpa congelada é comercializada no mercado interno bem como está sendo exportada (PINTO; GENU, 1984; BRAGA SOBRINHO et al. 1998/2011).

A pinheira é uma planta originária das Antilhas. Encontra-se disseminada em quase todos os continentes. $O$ fruto é conhecido na língua inglesa como "sugar apple" ou "sweet soup", "rinon" em espanhol e pinha, ata ou fruta-do-conde no Brasil. Foi introduzida no Brasil, precisamente na Bahia, na terceira década do século XVII. É cultivada no Brasil, comercialmente ou em pequenos plantios domésticos. Os Estados da Bahia e Alagoas são os maiores produtores. $\mathrm{O}$ fruto é muito apreciado pelo excelente sabor, porém apresenta muitas sementes aderidas à polpa (BRAGA SOBRINHO et al. 2012).

A planta da cherimólia é nativa das áreas agricultáveis das Cordilheiras dos Andes, incluindo países como a Bolívia, Equador, Peru e Colômbia. Foi disseminada para diversos países de clima tropical e subtropical. Pode ser encontrada no sul do continente europeu, Índia, Israel, Filipinas, Egito, sul dos Estados Unidos. É mais adaptada aos climas amenos subtropicais. Apresenta excelente qualidade e valor comercial, com sabor doce e sementes soltas da polpa. É conhecida na língua inglesa como "cherimoya", em espanhol "cherimole" e corssol Du Pérou, em francês.

A atemoieira é um híbrido interespecífico entre a cherimólia e a ata. Foi introduzida no Brasil na década de 1980. É cultivada principalmente nas regiões Sul e Sudeste do Brasil. Na década de 1990, este híbrido, variedade Gefner, foi introduzido com sucesso no Nordeste do Brasil. No País, já apresenta uma área superior a 1.500 hectares espalhados pelos Estados de São Paulo, Paraná e Nordeste do Brasil. Por se tratar de um híbrido, exige o uso de tecnologias diferenciadas para que sua produção seja economicamente viável. Esta fruta, a atemoia, vem tendo uma preferência especial pelos consumidores por apresentar algumas das boas características da cherimólia associadas a outras da ata. Entre outras vantagens, o fruto apresenta menor número de sementes, maior tempo de prateleira na pós-colheita, ausência de rachaduras, sabor diferenciado e teor de sólidos solúveis mais balanceado.

\section{AÇÕES DESENVOLVIDAS E AVANÇOS TECNOLÓGICOS}

O Sistema Agropecuário de Produção Integrada (SAPI), coordenado pelo Ministério de Agricultura, Pecuária e Abastecimento (MAPA) e com apoio do CNPq, EMBRAPA e outras instituições públicas e privadas coordenaram, a partir do ano de 2000/2001, 23 projetos de fruticultura com o envolvimento de, aproximadamente, 500 instituições públicas e privadas.

Vários foram os avanços tecnológicos obtidos em todos os elos da cadeia produtiva das frutas brasileiras. Entre outros, podem ser citados: redução significativa dos custos de produção em todas as frutas. Redução de $40 \%$ no uso de fertilizantes em maçã; uso racional de agrotóxicos, reduzindo em até $89 \%$ os inseticidas, melhorando os níveis de resíduos em frutos, contaminação ambiental e do homem do campo. Concomitantemente, a PI Frutas consolidou a inserção do Brasil no mercado exportador de frutas, embora ainda pequeno, mas competindo com qualidade e regularidade de produção (BRAGA SOBRINHO et al. 2007)

As primeiras ações e atividades realizadas com o projeto PI Anonáceas, em 2010, foram a divulgação do projeto junto às instituições públicas e privadas dos estados produtores e principalmente a formação de equipes multidisciplinares.

Como as anonáceas são culturas ainda com pouca expressão econômica, poucas instituições oficiais priorizavam ações de pesquisa, desenvolvimento e transferência de tecnologias voltadas para as culturas da pinha, graviola e atemoia. Para formar uma base de dados sobre a importância das anonáceas, antes da formulação do projeto, foi feito um levantamento a fim de se conhecer a área cultivada, importância econômica, social e potencial de demanda. O resultado mostrou que a pinha, a graviola e a atemoia eram cultivadas de forma 
muito extensiva, em algumas áreas quase de forma extrativista, em outras utilizando alguma tecnologia sem conhecimento prévio de seus benefícios. As Boas Práticas Agrícolas (BPA), os cuidados na pós-colheita, a logística de comercialização, o nível tecnológico dos produtores, o custo de produção e o uso adequado de agrotóxicos, enfim, toda a cadeia produtiva apresentava problemas, necessitando de ações corretivas urgentes a fim de tornar viável a exploração econômica dessas culturas. Entretanto, essas frutas apresentavam, na opinião de técnicos, produtores e consumidores, uma grande aceitação, indicando que havia um potencial de demanda significativamente grande. Outro ponto importante foi a demanda tecnológica externada pelos técnicos e produtores dessas frutas.

A coordenação do projeto teve que visitar os estados produtores, contatar instituições, apresentar o projeto e sensibilizar os agentes da importância de se implantar a Produção Integrada de Anonáceas, como uma ferramenta tecnológica para alavancar essas culturas e torná-las economicamente viáveis e socialmente justas.

Os primeiros contatos foram feitos no Estado de São Paulo com a CEAGESP, Coordenadoria de Assistência Técnica Integral - CATI, Instituto de Biociências da Universidade de São Paulo - IBUSP, Associação Brasileira dos Produtores de Anonáceas - ABPA, UNESP (Jaboticabal e Botucatu), Superintendência Federal de Agricultura e Cooperativas e Associações de Produtores. Algumas fotos abaixo mostram, de forma documental, pessoas, ações e eventos e os resultados dos frutos dessas parcerias em todos os estados produtores incluídos no projeto.

Com esse grupo formado, o projeto promoveu algumas reuniões para a elaboração e validação das Normas Técnicas Específicas de Anonáceas (NTEA). Nessa primeira fase, as normas foram elaboradas e validadas em nível técnico. Outras reuniões foram realizadas, agora com técnicos e produtores, para discussão, ajustes e a validação com os produtores, usuários dessas normas. Já com base nas NTEA, reuniões técnicas, encontros, dias de campo e cursos de curta duração ocorreram nos anos de 2010, 2011 e 2012, sob a coordenação do projeto.

No ano de 2011, a coordenação do projeto, juntamente com a Superintendência Federal de Agricultura de São Paulo, CEAGESP ABPA, associações de produtores e MAPA realizaram uma reunião com representantes do MAPA e ANVISA a fim de discutir-se a nova grade de agrotóxicos para ser usada em anonáceas. Esta lista já se encontra no MAPA e na ANVISA para análise e posterior aprovação e liberação do seu uso pelos produtores.

Reunião e visitas com produtores e técnicos às instalações e stands da CEAGESP foram realizadas com o objetivo de diagnosticar os problemas de logística de transporte, embalagens e comercialização das anonáceas. Com os trabalhos de capacitação dos técnicos e produtores, já há mudanças significativas quanto aos cuidados na colheita, pós-colheita, novas embalagens e transporte recomendados pela PI Anonáceas.

No Estado de Alagoas, foi formada também uma equipe de trabalho envolvendo várias instituições e pessoas, como parceiros como o MAPA local, SEBRAE, Universidade Federal de Alagoas UFAL, EMATER e Associações de produtores. Posteriormente, foram iniciadas visitas técnicas às principais áreas de produção (Palmeira dos Índios, Igaci e Estrela) a fim de que fossem levantados os principais problemas. O que se constatou foi a exploração de pinha, cerca de 2.000 hectares, de forma quase totalmente extrativista, praticada em nível familiar, com pouquíssimo acompanhamento técnico. Entretanto, cerca de 2.000 famílias dependem de forma direta da renda desses pequenos pomares. Existem intermediários que compram a produção e enviam de forma precária para outros mercados, principalmente CEAGESP (ALBUQUERQUE, 1997).

Reuniões técnicas, minicursos, seminários, dias de campo e um curso de 40 horas de capacitação para técnicos e produtores já foram realizados em Alagoas. Já como recomendação do PI Anonáceas, foi criada uma associação de produtores no município de Palmeira dos Índios. As NTEAs foram discutidas com técnicos. Após várias reuniões e encontros, as mesmas foram aprovadas pelos técnicos. Em reuniões posteriores, essas normas foram aprovadas e validadas por técnicos e produtores do Estado. Foi instituída e nomeada a Comissão da Produção Integrada de Anonáceas, formada por três técnicos do setor público e três representantes do setor privado e seus respectivos suplentes. Entre outros avanços constatados, podem ser citados como a adoção de itens das Boas Práticas Agrícolas (BPA) no campo e pós-colheita, maior cuidado na poda, adubação, uso de agrotóxico na colheita, higiene no campo e melhoria do manuseio, embalagem e transporte.

O Estado da Bahia, detentor de maior área de anonáceas do País, com cerca de 6.000 hectares de pinha e 2.000 de graviola, representa uma importância significativa para a sobrevivência da agricultura familiar. Como em outros estados, foi formada uma equipe de trabalho, constituída por técnicos da Agência Baiana de Defesa Agropecuária - ABDA, 
CEPLAC, Embrapa Mandioca e Fruticultura, MAPA - BA, SEBRAE, Universidade do Oeste Baiano, Prefeituras Municipais e Associações de Produtores. Foram também realizadas viagens técnicas para levantar e diagnosticar problemas na cadeia produtiva dessas culturas.

A produção de pinha concentra-se nos municípios polarizados por Irecê. Embora já existisse um pequeno nível de organização entre os produtores de pinha, constatou-se uma série de problemas em toda a cadeia. Várias reuniões técnicas foram desenvolvidas com produtores, nas quais foram discutidos os gargalos tecnológicos que influenciam a perda da qualidade dos frutos e consequente redução do preço ao produtor. Houve avanços nas BPAs com redução do uso de insumos e principalmente agrotóxico. Na pós-colheita, houve um avanço significativo do estímulo à substituição de caixas de madeira por caixas de papelão no transporte até a CEAGESP e outros mercados.

Foram realizadas reuniões, encontros técnicos, dias de campo, seminários, com o objetivo de sensibilizar as instituições técnicas e os produtores sobre a importância da pinha para cada município, bem como apresentar e discutir as NTEAs. Minicursos, dias de campo, encontros, palestras foram realizadas e recentemente um curso de 40 horas foi ministrado em Irecê para todos os técnicos e produtores de pinha dos municípios envolvidos.

Para a graviola, concentrada nos municípios polarizados por Itabuna-Ba, foram detectados a carência de inovações tecnológicas para melhorar a eficiência do cultivo, uma carga exagerada de agrotóxicos para o controle de pragas e doenças, problemas sérios de não adoção das BPAs, póscolheita, transporte e processamento. Mesmo procedimento adotado na região de Irecê, foram realizadas várias atividades de capacitação, dias de campo, palestras, minicursos e um curso de 40 horas. Entre outros avanços, já se podem verificar melhorias na colheita, pós-colheita e no processamento.

No Estado do Ceará, foram detectados áreas grandes, pequenas e dispersas de graviola, pinha e atemoia. Foi formada uma equipe de trabalho composta por técnicos da Embrapa, Emater e Associações de produtores. Os problemas detectados foram comuns aos outros estados. Reuniões técnicas, minicursos, encontros e dois cursos de 20 horas já foram realizados. Avanços quanto aos sistemas de produção adotados e as práticas de pós-colheita, embalagem e transporte já apresentam melhorias significativas.

Durante os três anos do projeto, foram publicados Manuais de Monitoramento e Controle de Pragas da Gravioleira, Cartilha de controle de Pragas da Pinheira para o Estado da Bahia, Cartilha de Monitoramento e Controle de Doenças da Gravioleira; Manual de Controle de Doenças da Pinheira. Outros documentos, como Cartilha de Pragas da Pinheira e de Pragas da Atemoieira, estão em fase de execução.

Portanto, neste artigo, de forma resumida, estão descritas as principais ações e avanço tecnológicos obtidos durante a vigência do projeto. É importante ressaltar que as anonáceas (pinha, graviola e atemoia) são culturas de grande potencial para o agronegócio de frutas no Brasil. Como são culturas que necessitam de um esforço de pesquisa considerável para elucidar e prover de soluções tecnológicas desde a parte de mudas, variedades, fisiologia da produção, colheita, pós-colheita e processamento, este projeto, também, veio enfatizar e motivar produtores, técnicos e instituições para inserir, em seus programas de pesquisa, projetos que contemplem vários gargalos tecnológicos destas culturas.

\section{REFERÊNCIAS}

ALBUQUERQUE, H.C. Situação atuação atual e perspectivas para as anonáceas no Estado de Alagoas. In: SÃO JOSÉ, A. R.; SOUZA, I.V.B.; MORAIS, O. M.; REBOUÇAS, T.N.H. (Ed.). Anonáceas, produção e mercado: pinha, graviola, atemoia e cherimólia. Vitória da Conquista: Universidade Estadual do Sudoeste da Bahia, 1997. p.150-152.

BRAGA SOBRINHO, R. et al. Pragas da gravioleira. IN: BRAGA SOBRINHO, R.; CARDOSO, J.E.; FREIRE, F.C.O. (Ed.). Pragas de fruteiras tropicais de importância agroindustrial. Fortaleza: CNPAT/ EMBRAPA, 1998. p.129-141.

BRAGA SOBRINHO, R.; GUIMARÃES, J.A.; ARAÚJO, E.L.; ASSIS, J.S.; MOREIRA, M.A.B.; MACEDO, L.P.M.; MESQUITA, A.L. M. Monitoramento de pragas na produção integrada do meloeiro. Fortaleza: Embrapa Agroindustria Tropical, 2007. 26p. (Documento, 142)

BRAGA SOBRINHO, R.; MESQUITA, A.L.M.; HAWERROTH, F.J. Manejo integrado de pragas na cultura da ata. Fortaleza: Embrapa Agroindustria Tropical, 2012. 25p. (Documento, 153) 
BRAGA SOBRINHO, R.; MESQUITA, A.L.M.; HAWERROTH, F.J.; SILVA, K.S.; KAVATI, R. Identificação e monitoramento de pragas na produção integrada da gravioleira. Fortaleza: Embrapa Agroindustria Tropical, 2011. 26p. (Documento, 142).

FACHINELLO, J.F. Situação e perspectivas da fruticultura de clima temperado no Brasil. Revista Brasileira de Fruticultura, Jaboticabal, v. 33, n.1 p. 109 - 120, 2011. Edição especial.

MAPA. Produção integrada no Brasil. Brasíla: Secretaria de Desenvolvimento Agropecuário e Cooperativismo, 2008. 1008p.
PINTO, A.C. de Q.; GENU, P.J.C. Contribuição ao estudo técnico-científico da graviola (Annona muricata L.). In:CONGRESSO BRASILEIRO DE FRUTICULTURA, 7., 1984, Florianópolis. Anais... Florianópolis: Sociedade Brasileira de Fruticultura/ EMPASC, 1984. v.2, p.529-546. 